\title{
Avaliação da toxicidade aguda e da atividade cicatrizante dos extratos etanólicos das folhas e raízes da Memora nodosa (Silva Manso) Miers (Bignoniaceae)
}

TRESVENZOL, L.M.F'; PARENTE, L.M.L.'; LINO JÚNIOR, R.S.2; FIUZA, T.S. '; BARA, M.T.F.'; CUNHA, L.C.'; LAXOR, L.P.'; MIGUEL, M.P. ${ }^{1}$; PAULA, J.R. ${ }^{*}$ *

${ }^{1}$ Universidade Federal de Goiás, Faculdade de Farmácia, Laboratório de Pesquisa em Produtos Naturais. , C. P. 131, Goiânia-GO. CEP: 74001-970. *pjrpaula@gmail.com, ${ }^{2}$ Universidade Federal de Goiás, Instituto de Patologia Tropical e Saúde Pública, $1^{a}$ Avenida esquina com Rua 235, Setor Universitário, Goiânia-GO. CEP 64605-050.

RESUMO: Memora nodosa (Silva Manso) Miers é uma espécie da flora do Cerrado cujas folhas e caules são utilizados popularmente no tratamento de feridas e úlceras externas, enquanto as raízes são empregadas para dores abdominais e no tratamento da sarna. O objetivo desse trabalho foi avaliar a toxicidade aguda dos extratos etanólicos das folhas e raízes nas doses de 2000 e $5000 \mathrm{mg} \mathrm{kg}^{-1} \mathrm{em}$ ratos e camundongos e a atividade cicatrizante das soluções aquosas contendo $2 \%$ desses extratos em feridas cutâneas em ratos. A contração das bordas das feridas foi avaliada por análises histológicas e morfométricas após 4, 7 e 14 dias de tratamento e por reação imunohistoquímica após 7 dias de tratamento. Os extratos etanólicos das folhas e raízes não apresentaram toxicidade na dose de $2000 \mathrm{mg} \mathrm{kg}^{-1}$ para ratos e camundongos e na dose de $5000 \mathrm{mg} \mathrm{kg}^{-1}$ para ratos. Nos camundongos, a dose de $5000 \mathrm{mg} \mathrm{kg}^{-1}$ dos extratos das folhas e raízes provocou alterações histológicas no fígado. Não foram observadas diferenças significativas na contração das feridas entre os grupos tratados com os extratos das folhas e das raízes e o controle após 4 e 7 dias de tratamento. Após 14 dias de tratamento, $50 \%$ dos animais tratados com o extrato das raízes apresentaram reepitelização total das feridas e reconstrução parcial dos anexos. A alantoína, isolada do extrato etanólico da raiz, pode ser considerada como um dos metabólitos secundários responsáveis pela aceleração da reepitelização.

Palavras-chave: Memora nodosa, cicatrização de feridas, alantoína, atividade angiogênica

ABSTRACT: Evaluation of acute and healing activity of ethanol extracts of Memora nodosa (Silva Manso) Miers (Bignoniaceae) leaves and roots. Memora nodosa (Silva Manso) Miers is a Brazilian Cerrado species whose leaves and stems are commonly used to treat external wounds and ulcers and the roots are used for abdominal pain and to treat scabies. The purpose of this study was to evaluate the acute toxicity of ethanol extracts from the leaves and roots of M. nodosa at 2000 and $5000 \mathrm{mg} \mathrm{kg}^{-1}$ doses in rats and mice and to evaluate the healing activity of aqueous solutions containing $2 \%$ of these extracts on skin wounds in rats. The contraction of the wounds was evaluated by histological and morphometric analysis after 4, 7 and 14 days of treatment and by immunohistochemistry analysis after 7 days of treatment. The ethanol extracts of leaves and roots presented no toxicity at a $2000 \mathrm{mg} \mathrm{kg}-1$ dose for rats and mice, and at a $5000 \mathrm{mg} \mathrm{kg}-1$ dose for rats. Histological changes in the liver of mice were verified with a $5000 \mathrm{mg} \mathrm{kg}-1$ dose of the leaf and root extracts. Macroscopic and histological differences were not observed in the contraction of wounds between the groups treated with leaf and root extracts and the control group after 4 and 7 days of treatment. After 14 days of treatment, $50 \%$ of the animals treated with the root extract presented total re-epithelialization of wounds and partial reconstruction of the annexes. Allantoin, isolated from the root ethanol extract, can be considered one of the secondary metabolites responsible for accelerating re-epithelialization.

Keywords: Memora nodosa, wound healing, allantoin, angiogenic activity

Recebido para publicação em 06/12/2009

Aceito para publicação em 23/01/2013

Rev. Bras. PI. Med., Campinas, v.15, n.3, p.423-430, 2013. 


\section{INTRODUÇÃO}

Memora nodosa (Silva Manso) Miers (Bignoniaceae) é uma planta do Cerrado cujas folhas e caules são usados popularmente como cicatrizante de feridas e úlceras externas e as raízes, no tratamento de dores abdominais e sarnas (Silva, 1998; Siqueira, 1988).

Em relação à cicatrização de feridas, nas últimas décadas, verificaram-se grandes avanços na compreensão dos diversos fatores e fenômenos relacionados com o processo de reparação tissular, bem como no desenvolvimento de novos recursos e tecnologias no tratamento. Entretanto, muito ainda precisa ser descoberto, em especial para ser utilizado em países subdesenvolvidos, onde a incidência e a prevalência de lesões crônicas são muito elevadas, principalmente em portadores de diabetes (Maldelbaum et al., 2003).

A cicatrização de feridas ocorre em três fases ou períodos sobrepostos: fase inicial, exsudativa ou inflamatória, fase proliferativa e fase de remodelação ou maturação. Cada uma dessas fases é caracterizada pela presença de infiltrados de células em locais específicos, que ocorre de forma integrada e coordenada por mediadores químicos, no sentido de otimizar o reparo. Segundo Hosgood (2006), as características macroscópicas dos estágios da inflamação e do debridamento para uma ferida aberta incluem coágulo sanguíneo, exsudato serosanguinolento e superfície sem tecido de granulação. A concentração de polimorfonucleares é alta no início do processo inflamatório e vai diminuindo com a evolução da cicatrização (Sanchez Neto et al., 1993). Durante a formação do novo tecido ocorre a proliferação fibroblástica e angioblástica (angiogênese) (Castelo Branco Neto et al., 2006; De Nardi et al., 2004; Hosgood, 2006; Rubin et al. 2006). Assim, de modo geral, o principal parâmetro avaliado na cicatrização de feridas em modelos animais é a redução do tamanho da ferida, normalmente expressa em termos de área. As análises histológicas do tecido de granulação e epidérmicos complementam a avaliação (Krishnan, 2006).

O uso popular, e mesmo tradicional, não são suficientes para validar as plantas medicinais como medicamentos eficazes e seguros. Assim, é importante realizar estudos farmacológicos e toxicológicos que comprovem ou não sua eficácia e avaliem sua segurança.

No que se refere aos ensaios toxicológicos pré-clínicos, a toxicidade aguda manifesta-se imediatamente ou com até 14 dias após a exposição de uma dose única de um xenobiótico por ingestão, inalação ou através da pele de animais e do homem. O propósito dos testes de toxicidade aguda é identificar uma dose claramente tóxica, sub-letal ou letal e identificar os órgãos alvos da substância em estudo (Bresolin \& Cechinel Filho, 2003).

Estudos prévios realizados com a $M$. nodosa evidenciaram a presença de saponinas e flavonóides nas raízes e saponinas, flavonóides e óleo essencial nas folhas (Tresvenzol et al., 2005). O óleo essencial apresentou o benzaldeído e o 1-octen-3-ol como componentes majoritários (Tresvenzol et al., 2009).

Os extratos etanólicos das folhas, caules e raízes da $M$. nodosa apresentaram fraca atividade antimicrobiana (Tresvenzol et al., 2009).

Visando ampliar os estudos sobre $M$. nodosa, essa pesquisa teve como objetivos avaliar a toxicidade aguda e atividade cicatrizante dos extratos etanólicos obtidos das folhas e raízes dessa planta.

\section{MATERIAL E MÉTODO}

\section{Material botânico}

O material botânico constituído por folhas e raízes de Memora nodosa foi coletado na região de Senador Canedo, Goiás, Brasil (16 45'1" S, 49 0,7' 50,6" W, a 717m de altitude), no mês de janeiro de 2006 e identificado pelo Professor Heleno Dias Ferreira da Universidade Federal de Goiás (UFG). Uma exsicata foi depositada no Herbário da UFG sob o registro 29981.

Preparação dos extratos etanólicos brutos O material foi seco em estufa com ventilação forçada a $40^{\circ} \mathrm{C}$ e triturado em moinho de facas até a obtenção dos respectivos pós. Os extratos das folhas e raízes da $M$. nodosa foram obtidos por maceração em etanol a $95 \%$, em temperatura ambiente, e concentrados em rotaevaporador a $40^{\circ} \mathrm{C}$ (Ferri, 1996).

Isolamento e identificação de metabólito secundário

Durante o processo de concentração do extrato etanólico bruto das raízes observouse a presença de um sólido amarelado aderido às paredes do balão. Esse sólido foi retirado e purificado por recristalização em etanol: água (1:1). Para a identificação desse composto foram utilizadas técnicas espectrométricas de ressonância magnética nuclear ( $\mathrm{RMN} \mathrm{C}^{13}, \mathrm{H}^{1}$ ) e Infravermelho (IV). Os espectros foram analisados e comparados com dados da literatura e com os espectros de um similar sintético PA (Sigma).

\section{Toxicidade aguda}

O experimento foi aprovado pelo Comitê

Rev. Bras. PI. Med., Campinas, v.15, n.3, p.423-430, 2013. 
de Ética em Pesquisas Médica Humana e Animal do Hospital das Clínicas/UFG, sob o protocolo no 057/07.

Para a avaliação da toxicidade aguda utilizaram-se ratos Wistar (Rattus norvegicus albinus) de ambos os sexos, com peso médio de $250 \mathrm{~g}$, oriundos do biotério da Universidade Federal de Goiás e camundongos (Mus musculus Swiss), fêmeas, peso médio de $24 \mathrm{~g}$, oriundos do biotério da UNICEUB - Centro Universitário de Brasília.

Os animais foram pesados e divididos de forma aleatória, em número de três por caixa, e adaptados no Biotério do Núcleo de Estudos e Pesquisas Tóxico-Farmacológicas da Faculdade de Farmácia/UFG, por um período de dez dias sob condições ambientais controladas (temperatura $22^{\circ} \mathrm{C} \pm 2{ }^{\circ} \mathrm{C}$, umidade relativa do ar de $50 \%$ a $70 \%$ e fotoperíodo claro/escuro de 12 horas). Água e ração foram oferecidos aos animais ad libitum, exceto nas quatro horas que antecederam à administração das amostras.

A investigação da toxicidade aguda seguiu, em linhas gerais, as diretrizes da OECD (2001) para teste de classe de dose aguda tóxica (Guideline 423).

Os extratos etanólicos das folhas e raízes da $M$. nodosa foram solubilizados em água/ DMSO $5 \%$ de forma a não exceder $1 \mathrm{~mL}$ por 100 $\mathrm{g}$ de peso corporal dos animais. As soluções foram administradas por via oral, através de gavagem.

Os ratos e os camundongos receberam uma dose única de $2000 \mathrm{mg} \mathrm{kg}^{-1}$ dos extratos etanólicos das folhas e das raízes. Posteriormente, outros grupos de ratos e camundongos receberam uma dose única de $5000 \mathrm{mg} \mathrm{kg}^{-1}$. Grupos tratados apenas com o veículo foram incluídos como controle negativo.

Os animais foram observados inicialmente a intervalos variados no dia da administração (10 minutos, 30 minutos, 1 hora, 2 horas, 4 horas, 6 horas, 12 horas e 24 horas) e, posteriormente, uma vez ao dia até o 14 dia. Nesse período, realizaram-se observações comportamentais sistemáticas (screening hipocrático), tabulandose as intensidades dos eventos de zero a quatro, assim discriminados: ausente (0), raro (1), pouco (2), moderado (3), intenso (4) de acordo com o modelo proposto por Malone \& Robichaud (1962) e Malone (1977). A quantidade de excretas e o consumo de água e ração foram avaliados a cada 72 horas.

No 14 dia, os ratos foram sacrificados em câmara de $\mathrm{CO}_{2}$ e os camundongos por deslocamento cervical, obedecendo aos princípios éticos de experimentação animal, propostos pelo Colégio Brasileiro de Experimentação Animal. Após o sacrifício dos animais, os órgãos (fígado, baço e rins) foram removidos e analisados a vista desarmada. Fragmentos desses órgãos foram retirados para avaliação histológica, fixados em formol tamponado a $10 \%$ por 24 horas, processados, corados com hematoxilina-eosina (HE) e analisados em fotomicroscópio óptico (LEICA, DMLS).

\section{Atividade cicatrizante}

Esse experimento foi aprovado pelo Comitê de Ética em Pesquisas Médica Humana e Animal do Hospital das Clínicas/UFG, sob o protocolo oㅡ 188/07.

Foram utilizados 54 ratos (Rattus novergicus albinus) da linhagem Wistar, fêmeas, com 60 dias de idade, peso entre 160 a $190 \mathrm{~g}$ no início do experimento, provenientes do Biotério Central da UFG.

Os animais foram adaptados no Biotério do Núcleo de Estudos e Pesquisas Tóxicofarmacológicas da Faculdade de Farmácia/UFG, por um período de dez dias e mantidos em gaiolas individuais de polipropileno, forradas com maravalha, sob condições ambientais controladas (temperatura $22^{\circ} \mathrm{C} \pm 2{ }^{\circ} \mathrm{C}$, umidade relativa do ar de $50 \%$ a $70 \%$ e fotoperíodo claro/escuro de 12 horas). Água e ração foram oferecidos aos animais ad libitum.

Os animais foram pesados e divididos, de forma aleatória, em 3 grupos de 18 animais cada, e receberam os seguintes tratamentos:

Grupo 1: animais tratados com água destilada.

Grupo 2: animais tratados com solução aquosa contendo $2 \%$ do extrato etanólico das folhas.

Grupo 3: animais tratados com solução aquosa contendo $2 \%$ do extrato etanólico das raízes. Cada grupo foi dividido em três subgrupos $(n=6)$ e avaliado após 4, 7 e 14 dias de tratamento.

Para o procedimento cirúrgico de instalação das feridas, os animais foram anestesiados (IM) com cloridrato de cetamina $\left(70 \mathrm{mg} \mathrm{kg}^{-1}\right)$ e cloridrato de xilazina (10 $\mathrm{mg} \mathrm{kg}^{-1}$ ) (Pachaly, 2006), posicionados em decúbito ventral e submetidos à tricotomia na região dorsal-cervical. Uma ferida circular, com 10 $\mathrm{mm}$ de diâmetro, foi confeccionado com um punch metálico na região depilada, de forma a retirar-se apenas a pele do animal.

Logo após a cirurgia e diariamente, no mesmo horário, foram instiladas $100 \mu \mathrm{L}$ das soluções testes e do controle nas feridas dos animais. As feridas foram avaliadas diariamente, verificando-se a presença ou ausência de hemorragia, exsudato e crosta.

Um subgrupo $(n=6)$ de cada grupo foi sacrificado em câmara de $\mathrm{CO}_{2}$ após 4,7 e 14 dias de tratamento, conforme protocolos preconizados por Lopes et al. (2005) e Garros et al. (2006).

Para a análise morfométrica, as feridas foram fotografadas nos dia zero (quando da

Rev. Bras. PI. Med., Campinas, v.15, n.3, p.423-430, 2013. 
realização da ferida), após 4,7 e 14 dias de tratamento utilizando-se uma câmara digital (Sony MPEGMOVIE VX) adaptada a um tripé e a uma distância constante de $27 \mathrm{~cm}$ da ferida. As imagens foram transferidas para um microcomputador $\mathrm{e}$ analisadas utilizando-se o software Image J 1.3.1 (NIH, EUA). Para avaliar o grau de contração da área da ferida foi utilizada a fórmula abaixo proposta por Al-Watban \& Andres (2000) e Oliveira et al. (2000).

$$
\text { Contração relativa da ferida }(\%)=\frac{(\text { Área lesada inicial }- \text { Área contraída })}{\text { Área lesada inicial }} \times 100
$$

Para a avaliação histológica, um fragmento de cada ferida foi retirado, fixado em formol tamponado a $10 \%$, processado e corado com hematoxilina e eosina (HE), de acordo com Luna (1968) e com corante picro-sírius (López \& Rojkind, 1985).

Os parâmetros, infiltrado inflamatório (polimorfonucleares ou mononucleares), fibrina, hemorragia e hiperemia foram avaliados após $4 \mathrm{e}$ 7 dias de tratamento, considerando os escores: ausente ( $0 \%$ ), discreto (até $25 \%$ ), moderado (> 25 a $50 \%$ ) e acentuado (> 50\%) (Biondo-Simões et al., 2006). Para avaliar o grau de reepitelização, após 14 dias de tratamento, adotaram-se os escores: total (epitélio recobrindo $100 \%$ da área lesada, com ou sem anexo) e parcial. A semiquantificação do colágeno foi realizada pela observação da intensidade da cor alaranjada das fibras coradas com picro-sírius e analisadas sob luz polarizada, de acordo com os escores propostos por BiondoSimões et al. (2006).

Para a análise imunohistoquímica, cortes de $5 \mu \mathrm{m}$ foram distendidos em lâminas histológicas silanizadas (3-aminopropil-triethoxisilane, Sigma). Após a desparafinização e a reidratação dos cortes, as lâminas foram colocadas em solução de citrato $\mathrm{pH} 6,0$, em banho-maria a $95^{\circ} \mathrm{C}$, por 30 minutos. Em seguida, as lâminas foram incubadas com albumina bovina (BSA) a 3\% em câmara úmida, à temperatura ambiente, por uma hora e posteriormente tratadas com anticorpo primário, VEGF (147) (Santa Cruz Biotechnology - 507), na diluição 1:500, em câmara úmida a $4^{\circ} \mathrm{C}$, por toda a noite. Após esta etapa, instilou-se sobre as lâminas o complexo estreptoavidina-biotina-peroxidase (kit LSAB - Dako K0690), em câmara úmida, à temperatura ambiente, por 20 minutos. A reação foi revelada com solução de diaminobenzidina (DAB), durante um minuto. Solução de PBS (tampão fosfato-salino) foi utilizada para as lavagens entre as etapas. Os cortes foram, então, contracorados com hematoxilina de Mayer, por 30 segundos, e as lâminas montadas com resina sintética (Sigma Aldrich, USA).

A leitura das lâminas foi realizada com auxílio do sistema de análise digital de imagem.
A contagem do número de vasos sanguíneos na área da ferida foi realizada utilizando-se planimetria por contagem de pontos com o auxílio do software GIMP 2.4.3. Um retículo quadrangular composto por 25 pontos foi superposto à imagem histológica e foram contados apenas os vasos nas intersecções presentes no campo visual, conforme modelos propostos por Ribattii et al. (2000) e Prado et al. (2006).

\section{Análise estatística}

Os resultados foram submetidos a tratamento estatístico utilizando-se o programa GraphPad InStat (Version 3.05 for Windows). Para a análise das variáveis paramétricas foi utilizado o teste t pareado e para as variáveis nãoparamétricas, o teste de Kruskal-Wallis e o pósteste de Dunn. Os resultados foram considerados estatisticamente significantes quando $p<0,05$ (Sampaio, 1998).

\section{RESULTADOS}

\section{Isolamento e identificação de metabólito secundário}

Ao concentrar-se o extrato etanólico das raízes da $M$. nodosa, verificou-se a presença um sólido amarelado com baixa solubilidade em etanol e razoável solubilidade em água. O sólido foi recristalizado, obtendo-se cristais levemente amarelos. Após a análise dos espectros de IV, $\mathrm{RMN}-\mathrm{H}^{1}, \mathrm{RMN}-\mathrm{C}^{13}$ o composto foi identificado como sendo a alantoína. Os espectros foram comparados com dados da literatura (Souza et al., 2004; Ferreira et al., 2000) e com o espectro de IV de uma amostra de alantoína PA. Destacaram os seguintes dados espectrais: IV (KBr, cm-1) 3439,89 (amina primária), 3344,19 (amida), 3220,73, 1781,81 (carbonila de amida), 1717,46 (carbonila de amida), 1661,88,

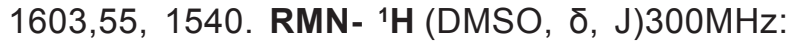
10,55(s, H-1), 8,07(s, H-3), 6,91-6,88 (d, H-6, $\mathrm{J}=8,4 \mathrm{~Hz}$ ), 5,80(s, H-8), 5,25(d, H-5, J=8,1Hz). RMN${ }^{13} \mathrm{C}$ (DMSO, $\left.\delta\right) 75 \mathrm{MHz}$ : C-2(157,57), C-4(173,84), C-5(62,62), C-7 $(157,00)$. 


\section{Toxicidade aguda}

Nenhuma morte ou sinal de toxicidade foram registrados durante o experimento da toxicidade aguda. A necropsia dos animais não evidenciou nenhuma alteração macroscópica. Na avaliação histológica não foram observadas alterações nos órgãos dos ratos e camundongos tratados com os extratos etanólicos das folhas e das raízes na dose de $2000 \mathrm{mg} \mathrm{kg}^{-1}$ e nos ratos tratados com a dose $5000 \mathrm{mg} \mathrm{kg}^{-1}$, em relação ao grupo controle. Os camundongos tratados com o extrato etanólico bruto das folhas (5000 mg kg-1) apresentaram, no fígado, degeneração hidrópica acentuada e foco inflamatório moderado com predomínio de polimorfonucleares. Nos camundongos tratados com o extrato etanólico bruto das raízes $\left(5000 \mathrm{mg} \mathrm{kg}^{-1}\right)$ evidenciou-se, no fígado, apenas focos inflamatórios discretos. Nenhuma alteração histológica foi observada no baço e nos rins.

\section{Atividade cicatrizante}

Não foi constatada perda de peso, autoagressão ou irritabilidade nos animais durante o período de realização do experimento.

Em relação ao tamanho das feridas, observou-se decréscimo da área lesada ao longo do tempo, mais acentuado entre o $7^{\circ}$ e $14^{\circ}$ dia de tratamento, tanto para o grupo controle, quanto para os grupos tratados. Após 4 dias de tratamento observaram-se, nos ratos do grupo controle, crostas delgadas, vermelhas, com exsudação serosanguinolenta em quatro animais e crostas mais espessas, castanhoescuras e secas em dois animais. No grupo 2 (tratado com o extrato das folhas) todos os ratos apresentaram feridas com crostas espessas e com coloração castanho-escura. Nesse grupo, exsudação serosanguinolenta foi observada em cinco animais. No grupo 3 (tratado com o

TABELA 1. Valores médios e desvio padrão da contração relativa das feridas cutâneas em ratos (\%) $(n=6)$ do grupo 1 e dos grupos 2 e 3 após 4 e 7 dias de tratamento.

\begin{tabular}{ccc}
\hline Grupos & \multicolumn{2}{c}{ Dias de tratamento } \\
& $\mathbf{4}$ & $\mathbf{7}$ \\
\hline 1 & $36,6 \pm 7,7$ & $42,2 \pm 9,1$ \\
2 & $29,8 \pm 13,3$ & $50,2 \pm 14,6$ \\
3 & $44,9 \pm 11,5$ & $31,0 \pm 17,6$
\end{tabular}

este t pareado $(P>0,05)$. Grupo 1: animais tratados com água destilada. Grupo 2: animais tratados com solução aquosa contendo $2 \%$ do extrato etanólico das folhas. Grupo 3: animais tratados com solução aquosa contendo $2 \%$ do extrato etanólico das raízes da $M$. nodosa.
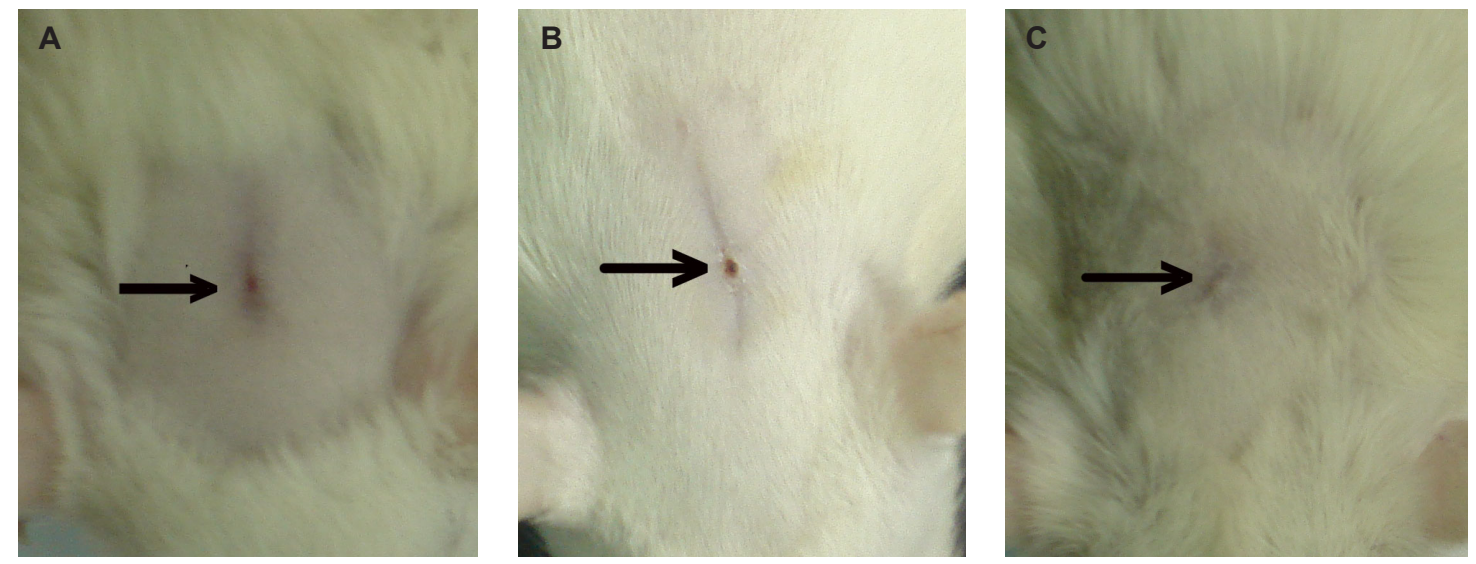

FIGURA 1. Aspecto macroscópico das feridas dos ratos, após 14 dias de tratamento. A - Grupo 1. B- Grupo 2. C - Grupo 3. Pequena crosta pode ser observada nos grupos 1 e 2. No grupo 3, cicatriz.

TABELA 2. Medianas das variáveis histológicas dos grupos 1, 2, e 3 após 4 e 7 dias de tratamento (n=6).

\begin{tabular}{|c|c|c|c|c|c|c|}
\hline \multirow[t]{3}{*}{ Variáveis histológicas } & \multicolumn{3}{|c|}{ Após 4 dias de tratamento } & \multicolumn{3}{|c|}{ Após 7 dias de tratamento } \\
\hline & \multicolumn{3}{|c|}{ Grupos } & \multicolumn{3}{|c|}{ Grupos } \\
\hline & 1 & 2 & 3 & 1 & 2 & 3 \\
\hline Fibrina & 3,0 & 3,0 & 2,0 & 3,0 & 3,0 & 2,0 \\
\hline Hiperemia & 2,5 & 2,0 & 3,0 & 2,0 & 2,0 & 2,0 \\
\hline Hemorragia & 3,0 & 3,0 & 3,0 & 2,5 & 2,0 & 2,0 \\
\hline Infiltrado inflamatório (PMN) & 3,0 & 3,0 & 3,0 & 3,0 & 2,5 & 2,5 \\
\hline
\end{tabular}

Teste Kruskal-Wallis $(p>0,05)$. 
extrato das raízes) todos os ratos apresentaram feridas com crostas delgadas, com coloração vermelho-escura e em três animais observouse exsudação sanguinolenta. Após 7 dias de tratamento todos os grupos apresentaram crostas espessas de cor castanho-escuras, com pouca ou nenhuma exsudação. Entre o $10^{\circ}$ e o $12^{\circ}$ dias de tratamento, vários animais perderam as crostas iniciais, que foram substituídas por outras de menor tamanho.

Não houve diferença significativa na contração relativas das feridas entre os grupos tratados (2 e 3) e o grupo controle (1) após 4 e 7 dias de tratamento (Tabela 1).

Após 14 dias de tratamento, os animais de todos os grupos apresentaram, no local da ferida, crostas pequenas ou cicatrizes. Crostas foram observadas nas feridas de cinco ratos do grupo 1 e em quatro do grupo 2 . No grupo 3 , dois ratos apresentaram pequena crosta e quatro uma pequena cicatriz (Figura 1).

\section{Avaliação histológica}

Não foram observadas diferenças significativas entre o grupo controle e os grupos tratados quanto às variáveis fibrina, hiperemia, hemorragia e infiltrado inflamatório após 4 e 7-dias de tratamento (Tabela 2)

Após 14 dias de tratamento, verificouse que as feridas dos animais do grupo 1 e 2 apresentavam reepitelização total e hiperplasia do epitélio, com predominância da camada espinhosa, mesmo nas feridas onde macroscopicamente ainda se evidenciavam crostas (Figura 2A). No grupo 3 a análise microscópica evidenciou reepitelização total, hiperplasia do epitélio com predominância da camada espinhosa em todos os animais e presença de anexos em $50 \%$ dos animais (Figura 2B).

Não foi observada diferença significativa na quantidade de colágeno dos grupos 2 e 3 em relação ao grupo controle, após 4,7 e 14 dias de tratamento (Tabela 3).
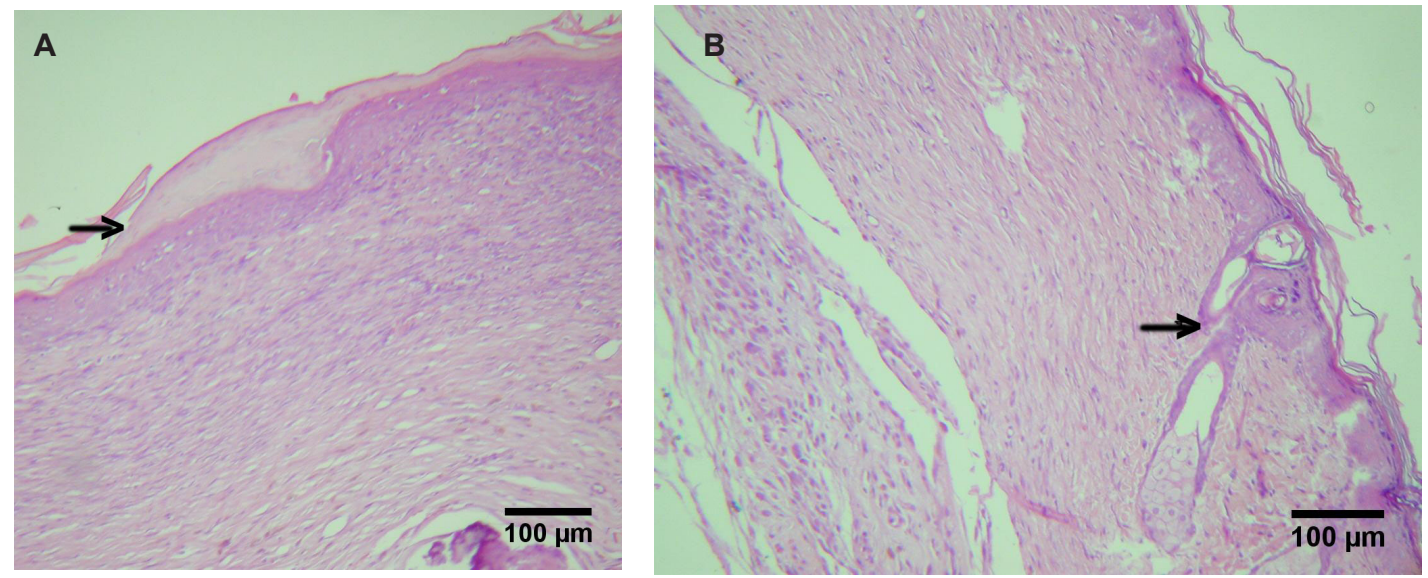

FIGURA 2. Fotomicrografias da derme de ratos dos grupos 2 e 3 após 14 dias de tratamento. A - Epiderme de rato do grupo 2 evidenciando reepitelização com crosta (seta). B - Epiderme de rato do grupo 3 evidenciando reepitelização com início da reconstituição dos anexos (seta). HE.

TABELA 3. Médias e desvio padrão da variável colágeno após 4, 7 e 14 dias de tratamento dos grupos 1, 2 e 3.

\begin{tabular}{cccc}
\hline Colágeno & Grupo 1 & Grupo 2 & Grupo 3 \\
\hline 4 dias & $0,83 \pm 0,4$ & $0,83 \pm 0,7$ & $1,16 \pm 0,4$ \\
7 dias & $1,33 \pm 0,81$ & $1,5 \pm 0,5$ & $1,66 \pm 0,5$ \\
14 dias & $2,83 \pm 0,4$ & $2,83 \pm 0,4$ & $2,66 \pm 0,51$ \\
\hline
\end{tabular}

ANOVA, Teste de Tukey $(p>0,05)$.

TABELA 4. Mediana do número de vasos sanguíneos na derme de ratos após 7 dias de tratamento.

\begin{tabular}{cccc}
\hline & \multicolumn{3}{c}{ Tratamentos } \\
\hline 7 dias & Grupo 1 & Grupo 2 & Grupo 3 \\
Medianas & 1,0 & $3,0^{*}$ & $4,0^{*}$ \\
\hline
\end{tabular}

Teste de Kruskal-Wallis e pós-teste de Dunn * $p<0,05$. 


\section{Imunohistoquímica}

$\mathrm{Na}$ planimetria digital por contagem de pontos realizada na derme de ratos tratados com as soluções aquosas contendo $2 \%$ do extrato etanólico das folhas e das raízes da $M$. nodosa, após 7 dias de tratamento, observou-se aumento significativo no número de vasos sanguíneos nos grupos 2 e 3 em relação ao grupo 1 (Tabela 4).

\section{DISCUSSÃO E CONCLUSÃO}

Nesse experimento optou-se por feridas com $10 \mathrm{~mm}$ de diâmetro e uma avaliação macroscópica e microscópica da lesão após 4, 7 e 14 dias de tratamento, conforme relatado por Oliveira et al. (2000), Castelo Branco Neto et al. (2006), Lopes et al. (2005), Santos et al., (2006), Speroni et al. (2002). Ratos da linhagem Wistar foram escolhidos para o experimento devido à facilidade de manuseio e acomodação e à maior resistência às agressões cirúrgicas e processos infecciosos (Garros et al., 2006). A ferida foi realizada na região dorsal-cervical para dificultar o contato do animal (lambida) e o autocanibalismo (Kashyap et al., 1995).

Aárea da ferida na derme dos ratos diminuiu gradativamente com a evolução do processo de cicatrização nos grupos tratados com os extratos das folhas, raízes e água destilada. A observação dos valores médios obtidos na mensuração da contração das feridas permitiu concluir que a retração centrípeta foi beneficiada, especialmente após 4 dias de tratamento para o grupo 3 e após 7 dias de tratamento, para o grupo 2 em relação ao grupo controle. Não houve diferença significativa quanto à contração relativa das áreas das feridas, após 4 e 7 dias de tratamento.

As características macroscópicas da fase inflamatória, descritas por Hosgood (2006), foram observadas após 4 dias de tratamento e confirmadas pela avaliação histológica para os grupos tratados com os extratos das folhas, raízes e água destilada. $\mathrm{Na}$ fase proliferativa constatou-se aumento do número de vasos sanguíneos na derme dos ratos tratados com a solução aquosa a $2 \%$ do extrato bruto das folhas e das raízes após 7 dias de tratamento. Verificou-se também que o grupo tratado com solução aquosa a $2 \%$ do extrato bruto das raízes apresentou maior atividade angiogênica que o grupo tratado com a solução aquosa a $2 \%$ do extrato bruto das folhas. Verificou-se aumento progressivo na quantidade de colágeno no decorrer do reparo da lesão, porém não foi observada diferença significativa entre os grupos.

Segundo Modolin \& Bevilacqua (1985), no final da fase proliferativa, ocorre a reepitelização da lesão, que é controlada pela chalona, um complexo glicoprotéico que estimula a atividade mitótica epitelial.
Nesse estudo, não se detectou diferença significativa entre os epitélios dos ratos tratados com solução aquosa a $2 \%$ do extrato bruto das folhas em relação ao controle. Em relação aos ratos tratados com solução aquosa a $2 \%$ do extrato bruto das raízes, verificou-se que a reepitelização foi mais precoce, pois a maioria dos animais não apresentava crosta sobre a nova epiderme e em $50 \%$ deles, observouse desenvolvimento parcial dos anexos. Esse fato pode estar relacionado com a presença da alantoína, isolada e identificada no extrato etanólico das raízes da $M$. nodosa. A alantoína estimula a proliferação celular, levando a uma rápida reepitelização da pele lesada (Merck Cosméticos, 2006; Budavi, 1989). Estudos mostraram que a alantoína auxiliou na reparação de feridas cirúrgicas (Willital \& Heine, 1994) e no tratamento da psoríase (Scott et al., 2001). O FDA (U. S. Food and Drug Administration) aprova a utilização da alantoína em cremes na concentração de $0,5 \%$ a $2 \%$, como produto de não-prescrição, para tratamento de pequenos cortes, arranhados, escoriações, queimaduras, queimaduras pelo sol ou pelo frio; na prevenção e proteção da pele e dos lábios contra rachaduras, irritações e ressecamentos (Allantoin, 2008). Embora não existam relatos da utilização popular das raízes da $M$. nodosa como cicatrizante de feridas, a presença da alantoína pode estar contribuindo na restauração da pele lesada em resposta ao prurido provocado pelo agente etiológico da sarna, o que justificaria sua utilização popular.

Pode-se concluir que os extratos etanólicos das folhas e raízes da $M$. nodosa, no modelo experimental de toxicidade aguda e nas doses avaliadas, foram atóxicos ou apresentaram baixa toxicidade. A solução aquosa a $2 \%$ do extrato bruto das folhas da $M$. nodosa não apresentou atividade cicatrizante. A solução aquosa a $2 \%$ do extrato bruto das raízes contribuiu apenas no processo final de reepitelização. A alantoína, isolada do extrato etanólico da raiz, pode ser considerada como um dos metabólitos secundários responsáveis pela aceleração da reepitelização.

\section{REFERÊNCIA}

ALLANTOIN, Supplement monograph. Flora Health Supplement Encyclopedia. Disponível em: <http://www. florahealth.com/flora/home/Canada/HeakthInformation/ Encyclopedias> Acesso em: 20 fev. 2008.

AL-WATBAN, F. A. H.; ANDRES, B. L. Effect of He-Ne laser $(632,8 \mathrm{~nm})$ and Polygen TM on $\mathrm{CHO}$ cells. Journal of Clinical Laser Medicine \& Surgery, v.18, n.3, p.14550, 2000.

BIONDO-SIMÕES, M. L. P.; ALCANTARA, E. M.; DALLAGNOL, J. C.; KELLY OKAMOTO YOSHIZUM, K. O.; TORRESIV, L. F. B.; BORSATO, K. S. Cicatrização de feridas: estudo comparativo em ratos hipertensos não tratados e tratados com inibidor da enzima conversora

Rev. Bras. PI. Med., Campinas, v.15, n.3, p.423-430, 2013. 
da angiotensina. Revista do Colégio Brasileiro de Cirurgiões, v.33, n.2, p.74-8, 2006.

BRESOLIN, T.M.B.; CECHINEL FILHO, V. Ciências farmacêuticas: contribuição ao desenvolvimento de novos fármacos e medicamentos. Itajaí: Ed. Univali, 2003. 239p.

BUDAVARI, S. The Merck index: an encyclopedia of chemicals, drugs, and biologicals. 11th ed. Rahway, N.J. USA: Merck \& CO, 1989. 1900p.

CASTELO BRANCO NETO, M.L. et al. Avaliação do extrato hidroalcoólico de Aroeira (Shinus terebinthifolius Raddi) no processo de cicatrização de feridas em pele de ratos. Acta Cirúrgica Brasileira, v.21, n.2, p.17-22, 2006.

DE NARDI, A.B. et al. Cicatrização secundária de feridas dermoepidérmicas tratadas com ácidos graxos essenciais, vitamina A e E, lecitina de soja e iodo polivinilpirrolidona em cães. Archives of Veterinary Science, v.9, n.1, p.1-16, 2004.

FERREIRA, D.T. et al. Constituintes químicos das raízes de Pyrostegia venusta e considerações sobre a sua importância medicinal. Química Nova, v.23, p.42-6, 2000.

FERRI, P.H. Química de produtos naturais. In: DI STASI, L.C. (Org.). Plantas medicinais: arte e ciência. Um guia de estudos interdisciplinar. São Paulo: Ed. Universidade Estadual Paulista, 1996. 230p.

GARROS, I.C. et al. Extrato de Passiflora edulis na cicatrização de feridas cutâneas abertas em ratos: estudo morfológico e histológico. Acta Cirúrgica Brasileira, v. 21, n. 3 p.55-65, 2006.

HOSGOOD, G. Stages of wound healing and their clinical relevance. Veterinary Clinics: Small Annal Practice, v.36, p.667-85, 2006.

KASHYAP, A. et al. Effect of povidone iodine dermatologic ointment on wound healing. The American Surgeon, v.61, n.6, p.486-91, 1995.

KRISHNAN, P. The scientific study of herbal wound healing therapies: Current state of play. Current Anaesthesia \& Critical Care, v. 17, n. 1-2, p. 21-27, 2006.

LOPES, G.C. et al. Influence of extracts of Stryphnodendron polyphyllum Mart. and Stryphnodendron obovatum Benth. on the cicatrisation of cutaneus wounds in rats. Journal of Ethnopharmacology, v.99, p.265-72, 2005.

LÓPEZ, L.N.A; ROJKIND, M. A simple micromethod for collagen and total protein determination in formalinfixed paraffin-embedded sections. Journal of hystochemistry and cytochemistry, v.33, p.737-43, 1985.

LUNA, L. G. Manual of histologic staining methods of the Armed Forces Institute of Pathology. 3rd ed. New York: Blakiston Division, McGraw-Hill, 1968. 258p.

MALDELBAUM, S.H.; DI SANTIS, E.P.; MALDELBAUM, M.H.S. Cicatrização: conceitos atuais e recursos auxiliares-Parte II. Anais Brasileiros de Dermatologia, v.78, n.5, p.525-40, 2003

MALONE, R.H. New natural products and a plant drugs with pharmacological, biological or therapeutical activity. In: WAGNER, H.; WOLFF, P. (Ed.) Pharmacological approaches to Natural Products Screening and Evalluation. Berlin: Springer, 1977. 269p.

MALONE, R.H.; ROBICHAUD, R.C. A Hippocratic screen form pure or drug material. Lloydia, v.25, n.4, p.23-53, 1962.

MERCK COSMÉTICOS. Disponível em: <http://www. merck.de/servlet/PB/menu/ 1393640_PRJ-MERCLPIGMENTE-COSME> Acesso em: 05 ago. 2006.

MODOLIN, M.; BEVILACQUA, R.G. Cicatrização de feridas. Síntese das aquisições recentes. Revista Brasileira de Clinica e Terapêutica, v.14, p.208-13, 1985.

OECD (Organisation for Economic Co-operation and Development). Guideline 423, Acute Oral Toxicity: Modified Up and Down Procedure, 2001. Disponível em: <http:www.oecd.org/ dataoecd/17/50/194370.pdf>. Acesso em: 01 set. 2006.

OLIVEIRA, S.T. et al. Formulações de confrei (Symphytum officinale L.) na cicatrização de feridas cutâneas em ratos. Revista da Faculdade de Zootecnia, Veterinária e Agronomia de Uruguaiana, v.7, n.1, p.61-5, 2000.

PACHALY, J.R. Terapêutica por extrapolação alométrica. In: CUBAS, Z.S.; SILVA, J.C.R.; CATÃO-DIAS, J.L. (Ed.). Tratado de animais selvagens - medicina veterinária. São Paulo: Roca, 2006. p.320-41.

PRADO, F.A. et al. Defeitos ósseos em tíbias de ratos: padronização do modelo experimental. Revista Odontológica Universidade, v.18, p.7-13, 2006.

RIBATTII, D. et al. The chick embryo membrane as model for in vivo research on anti-Angiogenesis. Current Pharmaceutical Biotechnology, v.1, p.73-82, 2000.

RUBIN, E. et al. Patologia: bases citopatológicas da medicina. 4.ed. Rio de Janeiro: Guanabara Koogan, 2006. 1650p.

SAMPAIO, I.B.M. Estatística aplicada à experimentação animal. Belo Horizonte: Fundação de Ensino e Pesquisa em Medicina Veterinária, 1998. 221p.

SANCHEZ NETO, R. et al. Aspectos morfológicos e morfométricos da reparação tecidual de feridas cutâneas de ratos com e sem tratamento com solução de papaína a 2 por cento. Acta Cirúrgica Brasileira, v.8, n.1, p.18-23, 1993.

SANTOS, M.F.S. et al. Avaliação do uso do extrato bruto de Jatropha gossypiifolia L. na cicatrização de feridas cutâneas em ratos. Acta Cirúrgica Brasileira, v.21, n.2, p.2-7, 2006.

SCOTT, L.J.; DUNN, C.J.; GOA, K.L. Calcipotriol ointment. A review of its use in the management of psoriasis. American Journal of Clinical Dermatology, v.2, n.2, p.95-120, 2001.

SILVA, S.R. Plantas do cerrado utilizadas pelas comunidades de região do Grande Sertão Veredas. Brasília: FUNATURA, 1998. 108p.

SIQUEIRA, J.C. Plantas medicinais: identificação e uso das espécies do cerrado. São Paulo: Ed. Loyola, 1988. 58p.

SOUZA, M.P. et al. Constituintes químicos ativos e propriedades biológicas de plantas medicinais brasileiras. Fortaleza: Ed. UFC, 2004. 445p.

SPERONI, E.; GOVONI, P.; GUIZZARDI, S.; RENZULLI, C.; GUERRA, M. C. Anti-inflammatory and cicatrizing activity of Echinaceae pallida Nutt. root extract. Journal of Ethnopharmacology, v.79, n.2, p.265-72, 2002.

TRESVENZOL, L.M.F. et al. Estudo farmacognóstico de Memora nodosa (Manso) Miers. Revista Eletrônica de Farmácia, v.2, n.2, p.221-3, 2005.

TRESVENZOL, L. M. F.; FIUZA, T. S.; PIMENTA, F.C.; ZATTA, D. T.; BARA, M T. F.; FERRI, P. H.; LIMA, A. B. M.; PAULA, J. P. Composição química do óleo essencial e atividade antimicrobiana da Memora nodosa (Bignoniaceae). Latin American Journal of Pharmacy, v.28, n.4, p.513-9, 2009.

WILLITAL, G.H.; HEINE, H. Efficacy of contractubex gel in the treatment of fresh scars ofter thoracic surgery in children and adolescents. International Journal Clinic Pharmacology Research, v.14, n.5/6, p.193202, 1994. 